\title{
MCDUFFEE, Michael B., Small Town Protestantism in Nineteenth-Century Germany. Living Lost Faith
}

\section{Nicolas Le Moigne}

\section{OpenEdition}

\section{Journals}

Édition électronique

URL : http://journals.openedition.org/ifha/1061

DOI : 10.4000/ifha.1061

ISSN : 2198-8943

Éditeur

IFRA - Institut franco-allemand (sciences historiques et sociales)

Référence électronique

Nicolas Le Moigne, « MCDUFFEE, Michael B., Small Town Protestantism in Nineteenth-Century Germany. Living Lost Faith », Revue de l'IFHA [En ligne], Date de recension, mis en ligne le 01 janvier 2004, consulté le 22 septembre 2020. URL : http://journals.openedition.org/ifha/1061 ; DOI : https://doi.org/ 10.4000/ifha.1061

Ce document a été généré automatiquement le 22 septembre 2020.

(C)IFHA 


\title{
MCDUFFEE, Michael B., Small Town Protestantism in Nineteenth-Century Germany. Living Lost Faith
}

\author{
Nicolas Le Moigne
}

M.MCD. se livre ici à un exercice désormais classique, la mise à l'épreuve microhistorique d'un schéma d'interprétation global - en l'occurrence l'idée de " sécularisation ». La petite ville de Butzbach, qui est l'objet de l'étude pour les années 1830-1872, est située dans l'une des régions alors les plus rurales d'Allemagne, le GrandDuché de Hesse-Darmstadt. La population, presque exclusivement luthérienne, y vit principalement de l'agriculture et de la cordonnerie. M.MCD. est à la recherche des évolutions de la conviction et de la pratique religieuse dans ce contexte rural, à un moment où le luthéranisme allemand change de visage. La thèse du livre est double : pour l'auteur, la sécularisation est d'abord l'intégration au luthéranisme de l'héritage rationaliste et, d'autre part, la transformation de l'identité religieuse en une donnée à la fois culturelle et séquentielle - le protestant est celui qui a été élevé dans le protestantisme, et chez lequel cette éducation continue, de manière irrégulière, à avoir des effets dans sa vie d'adulte. Cette double tendance permet d'expliquer le maintien de l'appartenance religieuse comme un critère identitaire fort, et ce jusqu'au XXe s., tandis que son contenu se dilue, qu'elle s'enracine de plus en plus dans la recherche du bonheur terrestre, au détriment de la quête du salut, et que ses liens avec les structures ecclésiastiques se distendent - d'où le sous-titre : « vivre la foi perdue ». À l'appui de ses dires, l'auteur se concentre dans un premier temps sur les rapports envoyés par les pasteurs à leur hiérarchie, qui dénotent d'une vague de " sécularisation " interne au clergé protestant : le rôle des pasteurs se déplace "vers le siècle ". L'éducation des fidèles, dans le sens de leur développement personnel, passe au premier plan des préoccupations, avant l'exercice du culte ou l'administration des sacrements. La place centrale que prend l'enseignement religieux conduit ensuite l'auteur à se pencher sur les manuels utilisés dans les écoles, et constate un étonnant chassé-croisé : les catéchismes d'inspiration rationaliste du début de la période cèdent la place à des méthodes appelant davantage à l'émotivité des fidèles, inspirées de Schleiermacher, 
avant un retour en force de l'orthodoxie à travers la réintroduction du catéchisme de Luther.

2 Bref, même si l'auteur a tendance à extrapoler les convictions des fidèles et leur rapport à la foi à partir de sources exclusivement ecclésiastiques, le propos de ce livre concis et clair reste stimulant, dans la mesure où l'étude micro-historique ne perd jamais de vue le problème général d'histoire européenne qui est en jeu ici.

3 Nicolas LE MOIGNE (MHFA) 